\title{
Claves de la tradición clásica en Aura de Carlos Fuentes*
}

Keys of the Classical Tradition in Aura by Carlos Fuentes

\author{
David GARCÍA PÉREZ \\ Centro de Estudios Clásicos, Instituto de Investigaciones Filológicas, UNAM \\ hyperion0z@yahoo.com
}

\begin{abstract}
RESUMEN: En este artículo se expone una comparación de los tópicos literarios que definen el relato de terror en la carta XXVII del libro 7 de Plinio el Joven y Aura de Carlos Fuentes, considerando algunos relatos intermedios que se entrecruzan hasta llegar a la novela breve del escritor mexicano, con el fin de analizar las relaciones literarias complejas en la recepción y recreación narrativas que se desarrollan en el marco de la Tradición clásica.
\end{abstract}

ABSTRACT: This article exposes a comparison of literary topics that define the horror story in the letter XXVII of Book 7 by Pliny the Younger and Aura by Carlos Fuentes, considering some intermediate stories that intertwine to reach the short novel of the Mexican writer, in order to analyze complex literary relations at the reception and recreation narrative given in the framework of the Classical Tradition.

Palabras Clave: Carlos Fuentes; Plinio el Joven; terror; Tradición clásica; recepción. KeYwords: Carlos Fuentes; Pliny the Younger; Horror; Classical Tradition; Reception. RECIBIDO: 7 de abril de 2017 - ACEPTADO: 23 de junio de 2017.

DOI: 10.19130/iifl.nt.2017.35.1.763

La perspectiva de la Tradición clásica se ha perfilado en muchos sentidos de modo simple: la recepción de una obra literaria del contexto A que es objeto de recreación en el contexto $\mathrm{B}$, una relectura lineal que explora los ecos temáticos y genológicos de, por lo menos, dos ámbitos literarios distintos y distantes, según una de las propuestas de análisis de la Literatura comparada; ${ }^{1}$ y si bien tal enfoque es conveniente en la medida en que comprueba cómo se produce la transición y la reelaboración de temas y motivos entre diferentes espacios literarios, en sentido amplio y desde el punto de vista historiográfico, también lo es que la mayoría de las

* Proyecto PAPIIT IN401615, "Crítica y teoría de la Antigüedad clásica: de Homero a Dante Alighieri”, Dirección General de Asuntos del Personal Académico, Universidad Nacional Autónoma de México.

${ }^{1}$ Cf. Guillén 2005, pp. 79-85. Utilizamos el término "recepción” en el sentido estricto que marca la acción y efecto de recibir, según el DRAE, en su primera acepción. No es nuestro objetivo utilizar en ningún momento los principios de la teoría de la recepción. 
ocasiones deja de lado las relaciones complejas que le son connaturales, ${ }^{2}$ esto es, las relecturas que median entre el punto de partida y el de llegada, que proponen diversas formas de interpretación. En efecto, cada lectura intermedia a su vez procede bajo el mismo modo complejo de relectura y recreación: cuando se aprecia que la línea de influencia no es meramente directa (A que determina o influye la creación de B), sino que acuden al texto una serie de ecos y reminiscencias, conscientes o no por parte del escritor, que, de cualquier manera, forman parte de la trama de la tradición literaria, nos encontramos con una reescritura que para su contexto actualiza cada uno de los afluentes literarios de los que se nutre. Siendo esto así, la maestría de una pieza literaria es notoria cuando el escritor parece ofrecer un texto que presenta rasgos tematológicos novedosos en todos los sentidos, porque ha sabido ocultar en el tejido los recuerdos propios que esa tradición hereda, ya sea porque establezca un texto fuente y/o porque entre esta posibilidad y el texto que formula la nueva relectura exista una serie de lecturas creativas intermedias en la cadena de la tradición. Originalidad no es ruptura con la tradición. Antes bien, es la atención fina a los avatares de ella lo que permite hacer las calas pertinentes de esa historia literaria y, así, proyectar otra lectura que se vuelca en escritura creativa. De otro modo, Octavio Paz afirmó que

la tradición de la ruptura implica no sólo la negación de la tradición sino también de la ruptura [...] Si la tradición significa continuidad del pasado en el presente, ¿cómo puede hablarse de una tradición sin pasado y que consiste en la exaltación de aquello que lo niega: la pura actualidad? ${ }^{3}$

Las relaciones complejas en la recreación literaria son la prueba del vínculo entre la raíz y sus relecturas y, al mismo tiempo, éstas son la versión del hic et nunc de los temas y motivos arquetípicos y prototípicos.

Si se pudiera contar con un panorama abarcador de la literatura occidental, se tendría una certeza de cómo, desde los tiempos de la poesía arcaica, aquélla es un continuo devenir de preservación y de relectura creadora que trabaja una y otra vez los temas y los motivos literarios. Tal acaecer es lo que se denomina "Tradición clásica", porque se parte de los modelos poéticos de Grecia y de Roma para arrogarse la madeja de

${ }^{2}$ Cf. García Jurado 2008, pp. 173-175.

${ }^{3}$ Paz 1974, p. 333. 
Ariadna que conduce por los caminos del entendimiento en los que cada época recrea la literatura, sus estructuras y sus contenidos. Bajo este procedimiento, es posible trazar lecturas a través del tiempo que descubren las influencias, sean edificadas éstas con plena conciencia y otras lo sean por el natural influjo que corre en el río de la tradición. El escritor que asume su lugar en la tradición literaria está atento a ese acaecer y se ejercita en la lectura creativa que parte desde una sola palabra hasta la trama y la urdimbre de la pieza completa. ${ }^{4}$ Hay que advertir que no se trata de la simple mímesis de la que ya Aristóteles trató en su Poética como motor de la creación, de la poíesis (1446a 13-16; 1451b 28-29), sino, además, de una acción estética que revisa y reelabora lo artísticamente aprendido para ofrecer la "novedad" del tema y del motivo, según su particular y peculiar visión. Es por ello que la tradición literaria va decantando la sustancia de los textos que, dada su trascendencia, llegan a ser apreciados como clásicos:

Nuestro mundo moderno es, en muchos aspectos, una continuación del mundo de Grecia y Roma [...], en la mayor parte de nuestras actividades intelectuales y espirituales somos nietos de los romanos y biznietos de los griegos, [sin el elemento grecolatino] nuestra civilización habría sido, no solamente distinta de lo que es, sino también mucho más raquítica y fragmentaria, menos pensadora y más materialista. ${ }^{5}$

Bajo este breve esbozo de la Tradición clásica y de algunos conceptos de la literatura comparada es que nos proponemos trazar algunas claves temáticas en Aura, novela de Carlos Fuentes, publicada en $1962 .{ }^{6}$ Esta corta narración se ha clasificado como un relato gótico, ${ }^{7}$ pues aborda un hecho que se considera fuera de la naturaleza real en el marco de un ambiente de oscuridad y misterio: el regreso de los muertos que reproducen un ciclo de destino al querer vencer a la muerte con la fuerza del amor, lo cual se adereza con elementos de hechicería y dentro de

${ }^{4}$ Guillén 2005, p. 272: "El complejo temático de una obra literaria se compone de una variedad de elementos entre los cuales existen relaciones o distancias más bien verticales, espaciales, que van de lo más visible a lo más profundo".

${ }^{5}$ Highet 1996, p. 11.

${ }^{6}$ Fuentes 1983, p. 539: "I published Aura in Spanish in 1962. The girl I had met as child in Mexico and seen re-created by the light of Paris in 1961 when she was twenty, died by her own hand, two years ago, in Mexico, at age forty". Las negritas son nuestras.

${ }^{7}$ Cf. Náter 2004, pp. 73-89. 
un perímetro donde las tonalidades de la oscuridad matizan cualquier reverberación. Históricamente, el estilo gótico fue la respuesta de una parte importante de la literatura europea, en especial de la inglesa, a la Ilustración, pues, a pesar de querer encontrar y demostrar que las creencias, las supersticiones, los prejuicios eran obstáculo para el desarrollo de un pensamiento cientificista, lo cierto es que los sentimientos como el terror a lo desconocido, que era aquello que se quería erradicar, podía no tener la buscada respuesta persuasiva. Se puede decir que, al contrario, la literatura ofreció temas y motivos literarios tomando como referente a la misma ciencia para decantar aspectos relevantes de lo gótico. Fue con The Castle of Otranto (1764), de Horace Walpole, que se marcaron las características de la literatura gótica a partir de una redefinición del mundo medieval frente a la naciente modernidad. ${ }^{8}$ La experiencia creativa de Fuentes durante su parisino año de 1961, no alude a La sorcière (1862) de Jules Michelet como referente perentorio de inspiración temática, no obstante que el epígrafe con el que abre Aura está tomado de este escritor francés. La figura de la bruja, según se colige del propio Fuentes, proviene de una pléyade de autores y obras que van perfilando la figura de Aura/Consuelo. Por esta razón y porque el interés del análisis se centra en trazar las relaciones literarias complejas de la Tradición clásica en Aura son los motivos por los que no haremos mayor referencia a Michelet, ${ }^{9}$ y nos centraremos en otros ramales que desembocan en la novela referida.

Ahora bien, de acuerdo con García Jurado la literatura gótica como tal tiene una raíz en la literatura latina, ${ }^{10}$ pues el miedo a lo extraño, lo oscuro, lo inexplicable es un sentimiento que aparece en la literatura de todos los tiempos y, quizá, haya que remontarse a Plinio el Joven (c. 61-113 d. C.) como punto de partida. Este autor romano escribió una serie de cartas que están recogidas en diez libros y que abordan temas de diversa índole. Entre dichas cartas se encuentra una dirigida a Licinio Sura: ${ }^{11}$ la XXVII del libro 7, en ella le pide opinión a su amigo sobre las

${ }^{8}$ Cf. Smith 2007, pp. 18-24.

${ }^{9}$ Por otra parte, la imagen de la bruja atendiendo las señas textuales de Fuentes ya ha sido abordada por diversos estudiosos, en particular por Gloria Durán en La magia y las brujas en la obra de Carlos Fuentes (1976).

${ }^{10}$ Cf. García Jurado 2008, pp. 174, 177, 186.

${ }^{11}$ Licinio Sura (c. 40-108 d. C.) fue mecenas de Marcial, senador y amigo íntimo del emperador Trajano. 
apariciones de fantasmas. Parece ser que estamos ante el primer cuento de espectros que de modo íntegro se ocupa de este tema, esto es, el personaje (el idolon, la aparición: 7, XXVII, 5) y el espacio en el que evoluciona como tal. En efecto, no obstante la brevedad del relato, en él se encuentran dos elementos esenciales del terror como tópico: la aparición del fantasma y el espacio en donde éste se manifiesta. El lugar, de hecho, puede verse, ya a partir de la carta de Plinio, como una extensión del fantasma, en razón de que es también fuente de terror: "Deserta inde et damnata solitudine domus totaque illi monstro relicta" (7, XXVII, 6). Dicha cualidad no pasó desapercibida para los escritores modernos que pudieron haber sido influidos por Plinio el Joven y por otros autores griegos y latinos.

La comparación que ahora vamos a trazar tiene por objeto reconocer las cercanías tópicas entre la carta de Plinio y Aura, considerando algunos otros relatos que se entrecruzan en la reelaboración textual; se trata de elementos compartidos por una larga cauda de narraciones las cuales tienen como elemento central la casa y su habitante, en una unidad que describe lo que la teoría literaria reconoce como gótico. No es la intención indicar que Carlos Fuentes fue influido directamente por la carta de Plinio, sino que su entramado se debe a lecturas intermedias de un cúmulo de escritores que parten del texto latino aludido; de hecho, como se lee, el novelista mexicano ofrece la fuente que sería el punto de arranque de Aura en el epígrafe que cita a La Bruja de Jules Michelet, influencia que no veremos por ahora. Pero aquí se trata de dos cosas distintas, pues lo que queremos resaltar de Plinio es la estructura, por muy simple que parezca, de personaje y casa, mientras que el desarrollo de la idea de Aura como hechicera parte de las ideas de Michelet en su tratado referido, tema que ya ha sido tratado con suficiencia. ${ }^{12}$

De acuerdo con la carta de Plinio, en Atenas existía una casa espaciosa y grande, pero de no buena fama e insalubre (7, XXVII, 5: "erat Athenis spatiosa et capax domus"), descripción que tiene eco en lo descrito por Fuentes: en Donceles 815, en el Centro de la Ciudad de México, ${ }^{13}$ había

${ }^{12}$ Cf. Pérez 1997, pp. 9-20.

${ }^{13}$ La creatividad del espacio de la ciudad y sus interiores - el Centro Histórico de la Ciudad de México y la casa de Aura-, tal vez sea el resultado de una mixtura entre las ciudades de París y México, ambientados góticamente, con la necrofilia como referente en películas, lectores y amigos de Carlos Fuentes en París en 1961, según lo narra el mismo escritor. Cf. Fuentes 1983, pp. 531-539. 
una casa que, como la de Atenas, no sería de lo más atractiva: infamis et pestilens dice Plinio de aquélla, y el autor de Aura a su vez refiere: "El olor de la humedad, de las plantas podridas, te envolverá mientras marcas tus pasos, primero sobre las baldosas de piedra, enseguida sobre esa madera crujiente, fofa por la humedad y el encierro". ${ }^{14}$ Felipe Montero, la contraparte medular de Aura, irá descubriendo poco a poco que aquel lugar es un espacio fuera de la realidad, encerrado en sí mismo, como si el aire ahí se hubiera petrificado con el abandono de la luz, apenas la suficiente para advertir que hay objetos y seres que la moran. La vivienda termina siendo el espacio en el que queda suspendido lo que resta de los muertos, sus fantasmas, su aura, su reflejo. La casa referida por Plinio estaba habitada por un anciano macilento y escuálido (macie et squalo$r e$ ), en medio de la podredumbre, pero no se trataba de un ser de este mundo, sino de un fantasma (idolon), cuya aparición estaba precedida por el ruido de cadenas (strepitus vinculorum). ${ }^{15}$ Quizá es ésta una de las imágenes de fantasmas que ha tenido luego abundantes recreaciones en la literatura occidental.

En Aura, cuando Felipe Montero decide acudir al lugar donde ofrecen un trabajo cuyas características parecen retratarlo de cuerpo completo, se hace explícita la sorpresa de que alguien viva ahí: "Siempre has creído que en el viejo centro de la ciudad no vive nadie". ${ }^{16} \mathrm{Y}$ si no vive nadie, ¿quién llama a Montero a través de los anuncios del periódico ${ }^{97}$ Nadie que fue alguien en otro tiempo: Consuelo/Aura que es el idolon precedido por el ruido de las palabras del periódico, objeto moderno en su contexto que sirve de vínculo para el contacto entre seres que aparentemente viven espacio y tiempo distintos, que funciona en el mismo nivel narrativo que el ruido de la tafeta de Aura ("- te das cuenta de que no la sigues con la vista, sino con el oído: sigues el susurro de la falda, el crujido de una tafeta - y estás ansiando, ya, mirar nuevamente esos ojos. [...] y

\footnotetext{
${ }^{14}$ Fuentes 1962, p. 14.

15 Plin., Ep., 7, XXVII, 5.

${ }^{16}$ Fuentes 1962, p. 13.

${ }^{17}$ Náter llama la atención sobre la posible influencia de "A rose for Emily", cuento de William Faulkner, en cuanto al contraste entre el espacio exterior marcado por la ciudad y el interior de la casa, donde se despliega "lo infernal gótico" (Náter 2004, p. 75). Sin embargo, salvo en el inicio de Aura donde Fuentes ofrece pinceladas del centro de la Ciudad de México, el contraste no es un elemento descriptivo determinante entre los mecanismos de la narración.
} 
se alejará, con ese ruido de tafeta, sin que hayas podido ver otra vez su rostro") ${ }^{18}$ y la resonancia de la campana que anuncia las comidas ("Te dará la espalda, se irá tocando esa campana, como los leprosos que con ella pregonan su cercanía, advierten a los incautos: 'Aléjate, aléjate' "). ${ }^{19}$ Además, Consuelo vive en medio de la ruina, de ratas y cosas viejas e inservibles, como el fantasma de la casa de Atenas ("Caminas, esta vez con asco, hacia ese arcón alrededor del cual pululan las ratas, asoman sus ojillos brillantes entre las tablas podridas del piso, corretean hacia los hoyos abiertos en el muro escarapelado"). ${ }^{20}$

En ambos casos los ruidos son soterrados, sólo los escuchan quienes traspasan los linderos de la propiedad. Con ese índice se marca la separación del espacio real y la otra dimensión habitada por los fantasmas: la frontera entre vivos y muertos es tan concreta como lo puede ser la casa habitada por los fantasmas, y son estos quienes atraen a su recinto a aquéllos mediante el cebo que les lanzan. En efecto, el ruido y la figura del fantasma ateniense ocasionaba que los habitantes de la casa pasaran en vigilia noches tristes y atroces a causa del miedo que provocaba todo aquello; de ahí que sobreviniera la enfermedad y el insomnio junto con el terror, para dar paso a la muerte (Plinio, 7, XXVII, 6: "vigiliam morbus et crescente formidine mors sequebatur"). Por lo mismo, nadie quería tomar la casa en alquiler, hasta que llega el filósofo Atenodoro. Como se observa, la casa se convierte en la tumba de quienes llegan a habitarla. Puesto que el miedo mata a los habitantes de la casa ateniense, ésta, como referente literario, se convertirá, en el tránsito de su tradición, en una suerte de personaje que ejercerá como ser vivo, capaz de matar de miedo por sí mismo a pesar de no tener vida propia. ${ }^{21}$

De modo semejante a lo que sucedía con quienes morían en la casa ateniense, Felipe Montero ya no pudo salir de Donceles 815, una vez

${ }^{18}$ Fuentes 1962, p. 21.

${ }^{19}$ Ibid., p. 54.

${ }^{20}$ Ibid., p. 39.

${ }^{21}$ En, efecto, no son pocos los casos en la literatura occidental donde la casa-personaje puede ser el eje del relato de terror. Cf., por ejemplo, Horace Walpole, The Castle of Otranto (1764); Edgar Allan Poe, The Fall of the House of Usher (1839); Charles Dickens, Bleak House (1853), Julio Cortázar, "Casa tomada" (1946). En la misma obra de Fuentes hay relatos en los que la descripción y función del hábitat es trascedente para la secuencia del terror, como sucede, por ejemplo, en "Chac Mool" (1954), Cumpleaños (1969) y en Vlad (2004, 2010). 
que cruzó el umbral donde vivía Consuelo/Aura. Cuando él desea ir a su morada por sus bártulos, porque se quedará a vivir en la casa del Centro Histórico para rescatar y concluir la redacción de las memorias del General Llorente, las mujeres no lo permiten, pues la belleza de Aura $\mathrm{y}$, sobre todo, el hechizo de los ojos verdes más hermosos y peligrosos vistos jamás, hacen caer al joven historiador en una ensoñación y dejadez inexplicables, y tras esa mirada se halla el sortilegio de Consuelo. Felipe Montero tiene miedo, pero la fuerza que Aura ejerce sobre él a través de su belleza, de su aparente debilidad - un eco del príncipe valiente a quien el destino le ha puesto como prueba rescatar a la doncella de las garras de la bruja-, lo hará permanecer en esa casa oscuramente verde donde quedará sepultado en vida, muerto, o muerto en vida para la eternidad. La racionalidad que puede haber en el historiador educado a la francesa no funcionó para exorcizar la brutal sexualidad de Aura y los hechizos verdes de Consuelo.

Por su parte, Atenodoro llega a vivir a la casa del fantasma ateniense y está resuelto a determinar de qué se trata todo aquel asunto: ordena la situación y su estancia de tal manera que pueda trabajar aquella noche, como si nada ocurriera, pues, como sucede en la noche de cualquier otra parte, únicamente se llega a percibir el silencio, pero éste es roto por el ruido de las cadenas de hierro, hecho que no asusta al filósofo: su disposición a escribir del modo más despreocupado hace que su voluntad sea más fuerte que lo que oye; sólo en el momento en el que el ruido se escucha cerca, primero en la puerta, y luego ya dentro de la habitación, vuelve la mirada y observa a la aparición que le habían referido. ${ }^{22}$ Literalmente el filósofo no le hace mucho caso, al decirle que espere un poco, porque el fantasma le indicaba algo con su dedo, pero éste de nuevo hace ruido con sus cadenas para que Atenodoro le preste atención.

El fantasma existe hasta que alguien repara en él. Este es un simplísimo, pero muy efectivo, motivo de la narración que marca la transición de la realidad al simulacro. El ruido del fantasma o la animación de la casa, en conexión con su caracterización, es parte sustancial de este motivo para el seguimiento de la secuencia narrativa del miedo que se apodera de los personajes. El caso de Atenodoro llama la atención también porque la explicación acerca de la materialidad del fantasma, en parte especulativa, se hace presente: el filósofo no se deja llevar por el

${ }^{22}$ Cf. Plin., Ep., 7, XXVII, 8. 
miedo, irracional como todos los sentimientos, que entra por los oídos y por la vista, sino que atiende a la razón y tiene la voluntad para saber qué sucede con la aparición. No es que niegue la presencia de ésta, sino que procede casi científicamente para descubrir el porqué de su existencia. Y el cuento de Plinio no deja de tener su parte, hasta cierto punto, jocosa cuando Atenodoro no pone atención de inmediato al requerimiento del fantasma y le pide un poco de paciencia, cuando o bien éste ya estaba acostumbrado a que todos le tuvieran miedo al punto de morirse, o bien nadie, hasta que llega Atenodoro, había reparado en que deseaba comunicar algo. ${ }^{23}$ En efecto, el fantasma de la casa de Atenas era de un insepulto que lo único que anhelaba era que alguien se diera cuenta de que yacía en el patio de la casa, donde seguramente murió encadenado y nadie se ocupó en darle sepultura; cosa que hace el filósofo al día siguiente: se exhuma el cadáver y los huesos se entierran a costa del erario público y de este modo la casa quedó liberada. ${ }^{24}$

Vale la pena aludir a un elemento más que pone de relieve la historia de fantasmas y que se acerca a otro tópico localizado en Aura: Luciano de Samosata (c. 125-185 d. C.) en El amigo de las mentiras reproduce, tópicos más tópicos menos, el relato de la carta de Plinio el Joven. Pero utiliza el mecanismo de la metamorfosis como cualidad del fantasma. Éste provoca miedo no sólo por su natural aspecto de aparición: sucio, desaliñado y de aspecto tan sombrío como la noche oscura (Philops., 31:

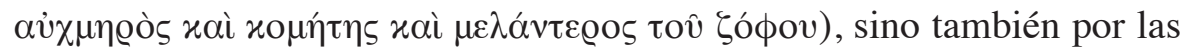
diferentes transformaciones en animales que experimenta, mismas que son usadas para atacar, pues el fantasma trocaba en perro, en toro y en

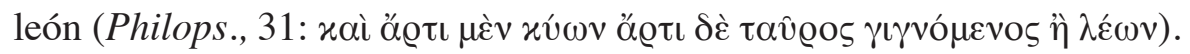
La metamorfosis es un componente narrativo que aquí indicamos como

\footnotetext{
${ }^{23}$ El pragmatismo con el que actúa Atenodoro hace recordar otro cuento de fantasmas donde este proceder es similar en otro momento de la tradición literaria: en The Canterville Ghost (1887), Oscar Wilde contrapone de manera irónica el sentido pragmático de la muy estadounidense familia Otis a las apariciones e intentos por asustar del fantasma Sir Simon de Canterville, quien finalmente descansa en paz gracias a la ayuda de Virginia, la joven hija del matrimonio Otis que descubre qué era lo que deseaba la aparición.

${ }^{24}$ Vale la pena indicar al margen que una historia de fantasmas que guarda relación tópica con la carta de Plinio ya se encuentra en la Mostellaria, comedia de Plauto (250184 a. C.), que también tiene a la ciudad de Atenas como espacio descriptivo. A su vez, esta pieza puede haber tenido influencia de una comedia griega titulada Phásma (El fantasma), de hacer caso a las dos menciones que de ésta hace el gramático Festo. Cf. López y Pociña 2007, p. 85.
} 
otro tópico más en Aura, que aparece de manera recurrente en los relatos de fantasmas, pues los tres personajes de esta narración - Aura, Consuelo y Felipe - en diversos momentos sufren cambios al tiempo que sus destinos se van intrincando hasta llegar a la relación sexual entre Aura anciana, que es Consuelo, y Felipe que va alcanzando en la inverosimilitud del tiempo y del espacio reflejada en la transformación a Consuelo joven, que de continuo troca en Aura:

Acercarás tus labios a la cabeza reclinada junto a la tuya, acariciarás otra vez el pelo largo de Aura: tomarás violentamente a la mujer endeble por los hombros, sin escuchar su queja aguda; le arrancarás la bata de tafeta, la abrazarás, la sentirás desnuda, pequeña y perdida en tu abrazo, sin fuerzas, no harás caso de su resistencia gemida, de su llanto impotente, besarás la piel del rostro sin pensar, sin distinguir: tocarás esos senos flácidos cuando la luz penetre suavemente y te sorprenda, te obligue a apartar la cara, a buscar la rendija del muro por donde comienza a entrar la luz de la luna plateada que cae sobre el pelo blanco de Aura, sobre el rostro desgajado, compuesto de capas de cebolla, pálido, seco y arrugado como una ciruela cocida. ${ }^{25}$

Puede decirse que la metamorfosis como componente de la naturaleza de los fantasmas se manifiesta en la alternancia de su presencia y de su ausencia, antes de funcionar mediante otro recurso literario. La aparición a la que se refiere Luciano de Samosata provoca un temor mayor a causa de los diferentes cuerpos que adopta, situación bastante común en los mitos griegos, donde las divinidades, sobre todo, son capaces de usar esa cualidad para alcanzar lo que se proponen. ${ }^{26}$ De igual modo, el estar y no estar es movimiento clave en Aura, porque la metamorfosis desdobla la naturaleza del propio ente: ella siempre es la misma en su juventud y en su vejez. El poder de la metamorfosis radica en que Consuelo halló la fórmula para hacer que Aura (el Amanecer) vuelva, es decir, que la juventud y todo lo que simbólicamente implica, en tanto que vida perenne, regrese en el tiempo circular e indefinido en el que se encuentran inmersos los personajes, y que también con la doncella retorne el amor

${ }^{25}$ Fuentes 1962, pp. 61-62.

${ }^{26}$ Cuando lo divino provoca un encuentro con lo humano, la manera de hacerlo puede ser a través de una transformación: "el resultado de estos encuentros es a menudo la metamorfosis. En el choque que lo enfrenta a lo divino, el ser humano puede perder el equilibrio y, bruscamente arrancado de su especie, convertirse en animal, vegetal o quedarse petrificado". Frontisi-Ducroux 2006, p. 15. 
-Dioniso / Llorente / Montero - para ser sacrificado en el altar de la anciana.

En términos del imaginario propio de los cuentos de fantasmas, ¿el asunto está en prestar o no atención a las apariciones? Hasta que Felipe Montero se da cuenta de que Aura es Consuelo y atisba que tal unidad no pertenece a este mundo, la metamorfosis se hace patente, pues no sólo son las dos mujeres las que truecan sus cuerpos: la belleza y la fealdad, la juventud y la vejez, la vida y la muerte. Felipe Montero lee el periódico y se topa con un aviso en el que prácticamente se le busca a él para desempeñar un trabajo sobre el rescate de unos documentos, pero no asiste, sino hasta la segunda comunicación, cuando el pago sube a $\$ 4000.00$ pesos mensuales ${ }^{27}$ Ingresa a la casa de Donceles y allí, sin saberlo, entra en contacto con el ánima conformada por Aura y Consuelo, con sus cuerpos en eterna metamorfosis, que son una unidad. Y en la carta de Plinio, el cartel que anuncia la venta o el alquiler de la casa ateniense habitada por el fantasma es el medio que atrae a Atenodoro, pues el precio le parece sumamente bajo: "Venit Athenas Philosophus Athenodorus, legit titulum auditoque pretio, quia suspecta vilitas, percunctatus omnia docetur ac nihilo minus, immo tanto magis conducit" (7, XXVII, 7). La comparación está a la vista: tanto el periódico como el cartel anuncian la casa que atrae al historiador y al filósofo respectivamente en sus contextos, seducidos en ambos casos por la cuestión monetaria: uno por el salario, el otro por la ganga que significa rentar la casa. Sin duda, hay ironía en establecer el interés material como el cebo con el que los seres de ultratumba atraen a los vivos a su espacio.

\footnotetext{
${ }^{27}$ Cantidad no despreciable para 1962, año de la publicación de Aura, tomando en cuenta que un dólar de los EUA equivalía a $\$ 12.50$ pesos mexicanos y que el costo de la vida era "aceptable". El pago ofrecido por Consuelo, entonces, era de \$320.00 dólares americanos. Si se considera la misma operación para enero de 2017, Felipe ganaría $\$ 6963.20$ pesos mexicanos, aproximadamente. Una miseria para un historiador con estudios en Francia; pero el costo de la vida es abismalmente diferente: en los tiempos de Consuelo y del General Llorente se pagaba $\$ 0.97$ pesos mexicanos por dólar americano; en los tiempos de Felipe Montero, \$12.50 pesos por dólar; actualmente (enero de 2017), se pagan $\$ 21.76$ pesos por dólar. Incluso considerando la "magia económica" de los Mexican Chicago Boys que quitó tres ceros al imaginario costo de la vida mexicana, la devaluación del peso desde entonces hasta ahora es de más de $7500 \%$. Hágase el cálculo correspondiente y se comprenderá, con suma empatía, que ningún Felipe Montero hoy entraría a casa alguna del Centro Histórico por tal cantidad (a no ser por ver a Aura nuevamente, si fuera el caso).
} 
A pesar de los indicios de misterio, el joven historiador no abandona la casa, sino que se queda ahí, por encima de la aversión y del terror, pensando en que puede rescatar a Aura, fugarse con ella, ser felices. Sin embargo, su presencia es necesaria porque es parte del rito que hará volver por un tiempo la juventud y la belleza de Consuelo en Aura, el medio por el cual se transita fugazmente a la vida, gracias a los hechizos de la anciana que traspasa la barrera del tiempo. Felipe Montero es el catalizador de la metamorfosis. A diferencia del cuento de Plinio donde se soluciona la historia felizmente, en Aura la casa se halla inmersa en un tiempo cíclico, resultado de la promesa de amor eterno que Felipe le hace a Consuelo, quien toma literalmente las palabras de su amado y por ello lleva a cabo los ritos necesarios para reencontrarse con él, en un espacio en el que realidad y artificio se confunden, porque el tiempo deja de existir una vez que se cruza el umbral.

Con los trazos comparativos anteriores, no se pretende decir que el escritor mexicano abrevó directamente de la carta de Plinio el Joven o de las otras fuentes literarias aludidas en tanto que relaciones complejas de recreación, como ya se adelantó, pues se trata de una recepción sintética que pasó por diversos momentos de rehechura; antes bien, en Aura hay una selección de tópicos y motivos que hacen de esta novela una imbricada pieza narrativa por la que cruzan diversas experiencias literarias. Si se ha apuntado como referente primario el texto de Plinio, es porque algunos escritores y teóricos del estilo gótico asientan como base de esta literatura la carta citada. Al respecto, abunda García Jurado que Plinio el Joven

sea probablemente el autor antiguo más significativo que inspira a los modernos relatos sobre apariciones fantasmales y que éstos, a su vez, relean y actualicen el relato latino. El hecho no es ni mucho menos puntual o aislado, sino que se inscribe dentro del rico diálogo que la literatura clásica mantiene con la literatura fantástica moderna, hasta el punto de que sería posible elaborar una rica y articulada antología de textos griegos y latinos extraída de las citas encontradas en estos relatos. $^{28}$

Es en el camino de la relectura y de la actualización de la tradición en el que se halla el texto de Fuentes, sin que se pueda asegurar una in-

\footnotetext{
${ }^{28}$ García Jurado 2006, http://www.culturaspopulares.org/textos2/articulos/garciajurado.htm.
} 
fluencia directa y, más bien, habría que inclinarse por atender que es la recepción de este texto en otros autores sobre todo del romanticismo los que sirvieron de puente entre la literatura griega y romana, y escritores más recientes. En efecto, si, como hemos visto, se considera a Plinio como raíz incidental de la literatura gótica en lo que respecta a Aura, la posibilidad de una influencia directa en esta novela de Sobre los hechos maravillosos del liberto Publio Elio Flegón, narrador de origen griego que vivió en época de Adriano (c. II d. C.), es todavía mucho más improbable. Sin embargo, las proximidades en cuanto a los tópicos son sugerentes.

Proclo es quien nos ha trasmitido la historia de Filinio contada por Flegón de Trales, pues la obra de este escritor no se conserva. ${ }^{29}$ Filinio se casó con Cratero a instancias de sus padres, un hombre acaudalado, no obstante que ella estaba enamorada de Macates. Al poco tiempo la joven muere pero regresa de ultratumba y visita a Macates quien es huésped de sus padres, Demóstrato y Caritó. Cierta noche, una doncella descubre a los amantes y le cuenta a sus amos. La madre reconoce a su hija y al siguiente día pide una explicación. Pero ella no vuelve durante el día, así que, al llegar la noche, Macates llama a los padres de Filinio, pues él tampoco acaba de creer del todo que ha estado yaciendo con una muerta. Ante los requerimientos de sus seres queridos, Filinio confiesa que ha vuelto a la vida porque los dioses infernales se lo han concedido, mas al revelar tal asunto cae muerta por segunda vez. Al amanecer, los padres se dirigen a la tumba de Filinio y no encuentran su cuerpo, sólo un anillo y una copa que fueron regalos que su amante le hizo. Y el cuerpo no está en la tumba porque ha quedado en la casa de sus padres, luego de su segunda muerte. Por consejo de un adivino, la joven es cremada en las afueras de la ciudad y se hacen rituales especiales para los dioses infernales. Macates, ante la pérdida de su amada, se suicida.

Como se puede observar, hay una serie de tópicos del cuento de Flegón de Trales que concurren en Aura: por principio se tiene en el centro de la historia a los dos amantes, Consuelo/Felipe y Filinio /Macates que no renuncian a su amor y éste pervive más allá de la muerte. En ambos relatos, es la mujer la que muere en primer término y es también la que

${ }^{29}$ Proclo, In Remp., 115-116; Frag. 1 Laurentianus. La reelaboración más conocida de La novia de Amfípolis atribuida a Flegón de Trales es la de Goethe: "Die Braut von Korinth" (1797). 
conoce el secreto para volver del más allá. No sólo regresa Consuelo misma, sino que es capaz de hacer retornar a su propio amado a través de la intervención de la siempre joven Aura, desde esta perspectiva del relato, pues ya hemos visto que a partir del enfoque de la metamorfosis el instrumento es Felipe Montero. La promesa de amor del General Llorente no fue entendida por Consuelo como una mera declaración amorosa: él la amaría para siempre, "siempre vestida de verde. Siempre hermosa, incluso dentro de cien años" ${ }^{30} \mathrm{Al}$ contrario, Consuelo entendió esa idea de modo literal y, ante la privación de su amado y de que pudiera tener descendencia, practica una suerte de herbolaria que concluye en hechicería, y más adelante en ritos que recuerdan el menadismo y las religiones mistéricas y de salvación de la antigua Grecia. ${ }^{31}$ De todo ello fue testigo el General Llorente todavía vivo:

Hoy la descubrí, en la madrugada, caminando sola y descalza a lo largo de los pasillos. Quise detenerla. Pasó sin mirarme, pero sus palabras iban dirigidas a mí. 'No me detengas - dijo-; voy hacia mi juventud, mi juventud viene hacia mí. Entra ya, está en el jardín, ya llega'... Consuelo, pobre Consuelo... Consuelo, también el demonio fue un ángel, antes... ${ }^{32}$

Y ahí finalizan las memorias que el General Llorente pudo escribir. Felipe Montero no tiene más material que leer. Pero el lector intuye que Llorente muere cuando Aura es poseída por la juventud eterna, ahí en su jardín verde oscuro donde siembra plantas de sombra, las mismas que utiliza para hacer que vuelva en una aura, es decir, en hálito, soplo de vida, e incluso aurora. A través de su mirada verde profundo puede lograr que el cuerpo que pide prestado para que su General se quede otra vez con ella, en la casa de Donceles, en un ritual eterno. Consuelo es un ángel caído, pero no lo escuchó ya de los labios de su marido, pues era necesario que éste feneciera como el macho cabrío del ritual que con uniformes movimientos ejecutan Aura en la cocina y Consuelo en sus habitaciones. Felipe, al presenciar el espectáculo de su propio sacrificio,

\footnotetext{
${ }^{30}$ Fuentes 1962, p. 41.

${ }^{31}$ El menadismo fue, por ejemplo, la pauta de la película italiana La strega in amore, dirigida por Damiano Damiani (1966), con guión del mismo director y de Ugo Liberatore basado en Aura. Se trata de una adaptación libre que pierde en gran medida los efectos narrativos que la novela contiene.
}

${ }^{32}$ Fuentes 1962, p. 57. 
empieza a comprender en dónde y en qué situación se halla. Mas ese conocer es lo que concluye finalmente el rito: la pasión amorosa termina porque el intruso acaba por saber qué pasa de raíz. ${ }^{33}$ Si Macates, en el relato griego, no hubiese confrontado a su amante con los padres de ella, quizá su amor hubiese sido eterno. Pero también en cierto modo tal vez lo es, ya que su suicidio le da la posibilidad de seguir a Filinio en el inframundo. Consuelo, por su parte, logra que el amor perviva más allá de la muerte al encontrar la fórmula mágica que le permite volver al General Llorente y a ella misma el reencontrarse en el momento exacto de su juventud, con su vestido de tafeta y sus penetrantes ojos verdes. ${ }^{34}$ En efecto, al sacrificio menádico acompaña, luego, la reunión carnal entre Consuelo/Aura y Felipe que refiere un ceremonial en el que emergen elementos del ritual católico, pero dispuestos de tal manera que Aura/ Consuelo es la conjunción de todos estos, porque ella preside la celebración, su cuerpo es la hostia con la que comulga con Montero y con el Cristo que es espejo del altar/Aura que yace en la cama:
Aura, de cuclillas, sobre la cama, coloca ese objeto contra los muslos cerrados, lo acaricia, te llama con las manos. Acaricia ese trozo de harina delgada, lo quiebra sobre sus muslos, indiferentes a las migajas que ruedan por sus caderas: te ofre- ce la mitad de la oblea que tú tomas, llevas a la boca al mismo tiempo que ella, deglutes con dificultad: caes sobre el cuerpo desnudo de Aura, sobre sus brazos abiertos, extendidos de un extremo a otro de la cama, igual que el cristo negro que cuelga del muro con su faldón de seda escarlata, sus rodillas abiertas, su costado herido, su corona de brezos montada sobre la peluca negra, enmarañada, entreve- rada con lentejuela de plata. Aura se abrirá como un altar. ${ }^{35}$

La fusión del erotismo y de los recursos del ritual católico dan como resultado una analogía de la pasión que representa Aura: ella misma, ahora, es el objeto del sacrificio que se ofrece al macho cabrío, Felipe, que ya se ha adentrado en las claves del ritual propiciatorio. Los dos perso-

${ }^{33}$ Fuentes 1983, p. 536: "La señora Consuelo, Aura and Felipe Montero joined this illustrious company, but with a twist: Aura and Consuelo are one, and it is they who tear the secret of desire from Felipe's breast. The male is now the deceived. This is itself a twist on machismo".

${ }^{34}$ La muerte inesperada o violenta es una de las causas por las que el muerto no descansa y regresa a pedir a los vivos que su ciclo sea cerrado de alguna manera. Así lo sugiere Luciano de Samosata cuando se refiere a los ahorcados, los degollados y los crucificados, así como todos aquellos que mueren de modo semejante. Cf. Philops., 29.

${ }^{35}$ Fuentes 1962, pp. 48-49. 
najes son ingredientes del sacrificio en un único cuerpo. Pero mientras él es clave de la revelación del misterio de la metamorfosis que va de Aura a Consuelo y viceversa, ella, en su plena juventud, es la oficiante, la ostia y la carne que es ofrecida para continuar con el ciclo del renacer amoroso.

Entre el menadismo con la incorporación de componentes del ritual católico y Aura hay relecturas intermedias que pudieron tener influencia en Fuentes. Cabe advertir, por otro lado, que quienes sí recibieron una notable influencia de la historia de Filinio y Macates fueron, entre otros, Goethe quien escribió "Die Braut von Korinth" (1797) a partir de la inclusión del relato atribuido a Flegón de Trales en un volumen de "descripciones de diversas personalidades maravillosas", publicado en 1666, en Alemania. ${ }^{36}$ Por su parte, Washington Irving, en su libro Tales of a Traveller (1824), narra una historia coincidente en varios tópicos: "The Adventure of the German Student". Y Theophile Gautier, de igual modo, se habría inspirado en aquella antigua historia para La morte amoreuse (1836). Quizá estas lecturas no fueron ajenas a Carlos Fuentes. Sin embargo, más cercana y quizá en un juego laberíntico de temas, la influencia más directa sea el cuento "La cena" (1916), de Alfonso Reyes. Como quiera que se haya dado la recepción, es posible ir de Aura hasta la carta XXVII del libro séptimo de Plinio el Joven para reconstruir la profunda tradición literaria que se halla recreada en la narración de Fuentes.

Por último, hay que llamar la atención sobre el nombre de Aura y su significación en algunos relatos de la antigüedad. ${ }^{37}$ De nueva cuenta, no se propone que Fuentes hubiera tenido una influencia directa a este respecto, sino que el título que eligió para su relato indicaría el renacer constante a través de los rituales de Consuelo. Aura es un nombre de origen griego; al español habría pasado a través del latín, pero ya se encuentra en textos literarios antiguos como un sinónimo de Aurora y, por extensión, del amanecer. Y éste es un sentido metafórico para la Aura del escritor mexicano, debido a que ella es la aurora atrapada en la casa verde y oscura, sin poder nunca amanecer. La fuente para sustentar una correspondencia con la novela de Fuentes en este asunto del nombre se

\footnotetext{
${ }^{36}$ Muñoz Acebes 2000, pp. 115-128.

${ }^{37}$ Sobre el nombre de Aura y su significación en el contexto de la novela, prácticamente trazando una sinonimia con la palabra "bruja", misma que no compartimos, cf. Mendoza 1989, pp. 191-192.
} 
halla en Ferecides de Atenas (450-400 a. C.), un logógrafo que contó una historia de amor, también con el aderezo de la muerte.

Céfalo y Procris se casan. Él pone a prueba a su esposa, para ello la abandona ocho años. Al regresar, Céfalo corteja a su propia mujer, disfrazado como alguien ajeno, de buena figura, talante y riqueza. Ella cae finalmente ante los requerimientos del supuesto pretendiente, que no es otro que su mismo esposo. La aceptación de Procris la hace ver como traidora ante los ojos de su marido; pero, luego de la confrontación, los esposos se perdonan. Una vez reconciliados, él a menudo salía del hogar y ella desconfiaba de su proceder. Un sirviente le indica hacia dónde iba aquél en sus continuos abandonos. Procris encuentra en la montaña a su esposo mirando al horizonte y gritando "¡Oh Aura, Aura, ven aquí"; al escuchar que algo se acerca, Céfalo, excelente cazador, da la vuelta de inmediato y caza a su propia esposa, creyendo que es una presa. Como se ve, en este relato al último muere Procris, como si su debilidad ante los requerimientos amorosos de su marido disfrazado y luego plenamente identificado fuera, a fin de cuentas, una grave falta que se paga con la muerte.

De hecho, este relato es fuente de inspiración de otras narraciones, como "El curioso impertinente", novelita insertada en la primera parte de Don Quijote de la Mancha, donde la mayoría de los elementos tópicos coinciden con el relato atribuido a Ferecides ${ }^{38}$ Pero para el caso que nos ocupa, se ha querido referir el resumen del cuento para llegar a la invocación que hace Céfalo a Aura, el amanecer, y que es motivo de los celos de Procris. No hay mayores elementos de comparación más que el nombre, pero parece significativo que sea esta deidad, porque lo es para la tradición antigua, la que tenga relación con el tema amoroso que, por alguna u otra razón, se ve truncado y la invocación como parte de un ritual que hace que tal amor perdure. Tanto es así que si para el relato de Ferecides, Aura parece un personaje o motivo incidental, siglos más tarde (entre el II a. C. y el II d. C.) Antonino Liberal coloca a Aura en un primer plano al hacer de ella una deidad despechada, pues se enamora de la belleza de Céfalo al punto de raptarlo, no obstante que luego lo deja ir con Procris porque él no la olvida, no sin antes sembrar en él la desconfianza sobre la fidelidad de su esposa. ${ }^{39}$ Este mismo tópico fue

${ }^{38}$ Cf. García Pérez 2013, passim. A propósito de la influencia de Cervantes en Fuentes en torno a Aura, cf. Bell 1997, pp. 105-114.

${ }^{39}$ Anton. Lib., XLI, passim. 
tomado por Ovidio en sus Metamorfosis para recrear, por lo menos en una tercera versión, la historia de Céfalo y Procris. ${ }^{40}$

Si bien es cierto que Carlos Fuentes a lo largo de su vasta obra hace alusiones directas que revelan con claridad sus lecturas de autores clásicos, en Aura advertimos una recepción que ha pasado por diversas etapas de recreación, de modo que, como ya se dijo al principio, no se trata de un proceso lineal - la recepción y re-creación de A en $\mathrm{B}-$, propio de la tradición clásica, sino una relación compleja de relecturas y de reelaboraciones literarias en la medida en la que en aquel relato acuden diversas voces que han aportado elementos peculiares al entramado gótico, y todas ellas tienen su punto de partida en la literatura griega y romana. El tejido de Aura es de una trama sutil, donde apenas si se advierten los hilos tomados de aquí y de allá para hacer la urdimbre de su texto, pues "no hay un orden ancestral restaurable ni un universo único en su normatividad. Habrá niveles múltiples de la lectura que sometan a prueba los múltiples niveles de la realidad". ${ }^{41}$ Muy probablemente Fuentes no puso más que en marcha los motivos y la trama de distintos relatos que alcanzan el espacio clásico de las literaturas griega y romana sin tener la plena conciencia de esta singularidad creativa. En esto quizá reside la originalidad en el marco de la tradición literaria, en no socavar el edificio textual, sino en proyectarlo con la peculiar visión de quien se halla inmerso en la tradición literaria de los clásicos griegos y romanos.

\section{BIBLIOGRAFÍA}

Antonino Liberal, Metamorfosis, intr. de Esteban Calderón Dorda, trad. y notas de María Antonia Ozaeta Gálvez, Madrid, Gredos, 1989.

Aristóteles, Poética, ed. trilingüe, intr. y notas de Valentín García Yebra, Madrid, Gredos, 1999.

Bell, Michael, "The Fuentes of Fuentes and the Aura of Aura: Carlos Fuentes' Up-dating of a Cervantean Theme", Inti: Revista de literatura hispánica, 45, 1997, pp. 105-114.

DuRÁn, Gloria, La magia y las brujas en la obra de Carlos Fuentes, México, Universidad Nacional Autónoma de México, 1976.

\footnotetext{
${ }^{40}$ Ov., Met., VII, 682 ss.

${ }^{41}$ Fuentes 1976, p. 93.
} 
Frontisi-Ducroux, Françoise, El hombre-ciervo y la mujer-araña. Figuras griegas de la metamorfosis, Madrid, Abada Editores, 2006.

Fuentes, Carlos, Aura, México, Era, 1962.

Fuentes, Carlos, "On Reading and Writing Myself: How I Wrote Aura", World Literature Today, 57/4, 1983, pp. 531-539.

Fuentes, Carlos, Cervantes o la crítica de la lectura, México, Joaquín Mortiz, 1976.

GARCíA JuRADO, Francisco, "Los cuentos de fantasmas: entre la literatura antigua y el relato gótico", Culturas Populares. Revista electrónica, 2, 2006. Disponible en: <http://www.culturaspopulares.org/textos2/articulos/garciajurado.htm>.

GARCíA JURADO, Francisco, "Literatura antigua y modernos relatos de terror: la función compleja de las citas grecolatinas", Noua Tellus, 26/1, 2008, pp. 169204.

García PÉrez, David, "Génesis e influencia de un mito: El curioso impertinente, en A. V., Cervantes novelista antes y después del Quijote, Guanajuato, Museo Iconográfico del Quijote, Universidad de Guanajuato, 2013, pp. 17-39.

GuILlÉn, Claudio, Entre lo uno y lo diverso. Introducción a la Literatura Comparada (Ayer y hoy), Barcelona, Tusquets, 2005.

Highet, Gilbert, La tradición clásica, I, México, Fondo de Cultura Económica, 1996.

López LóPez, Aurora y Andrés PociÑa Pérez, Comedia romana, Madrid, Akal, 2007.

Luciano De Samosata, Obras, I, ed. y trad. de José Alsina, Barcelona, Alma Mater, 1962.

MendozA, Mario, “Aura de Carlos Fuentes: un aquelarre en la calle de Donceles 815”, Anales de Literatura Hispanoamericana, 18, 1989, pp. 191-201.

MuÑOZ ACEBES, Francisco Javier, "El motivo de la mujer vampiro en Goethe: Die Braut von Korinth”, Revista de Filología Alemana, 8, 2000, pp. 115-128.

NÁTER, Miguel Ángel, "La imaginación enfermiza: la ciudad muerte y el gótico en Aura de Carlos Fuentes", Revista chilena de literatura, 64, 2004, pp. 73-89.

Ovide, Les Métamorphoses, ed. y trad. de G. Lafaye, Paris, Les Belles Lettres, 1957.

PAZ, Octavio, Obras completas. La casa de la presencia. Poesía e historia. Los hijos del limo, 1, México, Fondo de Cultura Económica, 1974.

Paradoxógrafos griegos, rarezas y maravillas, intr., trad. y notas de F. J. Gómez Espelosín, Madrid, Gredos, 1996.

PÉREZ, Genaro J., "La configuración de elementos góticos en 'Constancia', Aura y 'Tlactocatzine, del jardín de Flandes' de Carlos Fuentes”, Hispania, 80/1, 1997, pp. 9-20.

Pline Le Jeune, Lettres, II, ed. y trad. de Anne-Marie Guillemin, Paris, Les Belles Lettres, 1955.

Reyes, Alfonso, La cena, México, Conaculta, 2013.

SMITH, Andrew, Gothic Literature, Manchester, Edinburg University Press, 2007. 